\title{
Aulas práticas em ciências: concepções de estagiários em licenciatura em biologia e a realidade durante os estágios
}

Lessons in science practices: trainees conceptions degree in biology and reality during the stages

Tamiris Franco de Castro ${ }^{1}$ Andréa Inês Goldschmidt ${ }^{2}$

\section{Resumo}

Atividades práticas são apontadas como um recurso importante para o ensino de Ciências. Objetivou-se investigar a concepção de atividades práticas e como estas se fazem presentes na sala de aula, quando os docentes em formação têm a possibilidade de planejarem suas ações durante o estágio. Trata-se de uma pesquisa quali-quantitativa, direcionada a vinte licenciandos, participantes do Estágio Curricular Supervisionado em Ciências Biológicas no Ensino Fundamental II. Também foram investigados os planos de aulas dos estagiários, a fim de identificar as estratégias didáticas utilizadas. Os dados foram submetidos à análise de conteúdo e revelaram que os docentes em formação não apresentam clareza sobre o conceito de aulas práticas, compreendem a importância das mesmas e seu papel como facilitador na aprendizagem, mas pouco usam estas, durante suas aulas. Apontaram como dificuldades, a falta de tempo para a realização de experimentos, falta de laboratório e recursos, receio quanto à indisciplina, falta de criatividade e também dificuldade em aliar a teoria-prática. Os acadêmicos priorizam ainda uma visão dissociativa, que desintegra a teoria da prática, sendo necessária uma reflexão deste paradigma.

Palavras chave: Aulas Práticas; Ensino em Ciências; Formação Docente.

\section{Abstract}

Practical activities are seen as an important resource for the teaching of science. This study aimed to investigate the design of practical activities and how these are present in the classroom when teachers in training are able to plan their actions during the stage. It is a qualitative and quantitative research, directed to twenty undergraduates, participants Supervised in Biological Sciences in Elementary Education II. Also the lesson plans of the trainees were investigated in order to identify the teaching strategies used. Data were submitted to content analysis to organizational categories and revealed that teachers in training have no clarity on the concept of practical classes, understand the importance of them and their role as a facilitator in learning, but little use these during their classes. They pointed as difficulties, the lack of time to conduct experiments, lack of laboratory and resources, fear about the lack of discipline, lack of creativity and also difficult to combine

\footnotetext{
${ }^{1}$ tamy.franco@hotmail.com

2 andreainesgold@gmail.com
} 
theory and practice. Scholars still prioritize a dissociative vision, which disintegrates the theory of practice, requiring a reflection of this paradigm.

Keywords: Practical Classes; Teaching in Science; Teacher Education.

\section{Introdução}

A realização desse estudo pautou-se na ideia de que os licenciandos trazem para a sala de aula, teorias e explicações sobre o seu cotidiano, oriundas de várias fontes, tais como conversas com amigos e familiares, mídia, contextos social e cultural, entre outras (CARRETERO, 1993). Estas apresentam um caráter espontâneo, advinda de uma aprendizagem espontânea, social e culturalmente situada e dependente da natureza das experiências e interações de cada indivíduo. Além disso, as concepções prévias são extremamente resistentes (CARRETERO, 1993; POZO e GÓMEZ CRESPO, 1998).

Neste contexto, Goldschmidt et al (2016) afirmam que torna-se importante compreender a visão que alunos em formação docente têm do seu papel enquanto professor, cabendo aos professores formadores a tarefa de questionar e mostrar as determinantes dessas ideias. Caso contrário, corre-se o risco da construção da identidade docente não sair das amarras resistentes dessas concepções prévias.

O modelo tradicional de ensino é ainda amplamente utilizado por muitos educadores nas nossas escolas de Ensino Fundamental e Médio. Segundo Carraher, Carraher e Schliemann (1985), tal modelo de educação trata o conhecimento como um conjunto de informações que são simplesmente passadas dos professores para os alunos, o que nem sempre resulta em aprendizado efetivo.

$O$ ensino de Biologia pode ser ainda hoje, um desafio para muitos professores e alunos. Em geral, vemos que a insatisfação dos alunos ocorre por acharem que a Biologia é uma disciplina difícil, visto que exige uma grande capacidade de memorização, pelos inúmeros conteúdos teóricos abordados no dia a dia escolar.

Fracalanza, Amaral e Gouveia (1987) discutem que há um grande número de especialistas em ensino em Ciências que propõem a substituição de aulas meramente expositivas, baseadas nos livros didáticos, por atividades práticas.

Na tentativa de melhorar a dinâmica das aulas, a interação e participação dos alunos, o professor deve desenvolver estratégias e alternativas que possam simplificar a linguagem usada em sala de aula, tentando torná-la mais simples e coerente. Uma das alternativas é a realização de aulas práticas.

Dentro desse contexto se faz necessário ter uma concepção clara do que se refere aula prática, que para Hodson (1994) se caracteriza como qualquer atividade em que os alunos estejam ativos e não passivos; e ainda, reconhece esta modalidade como meio eficiente para melhorar o aprendizado, fortalecer explicações teóricas, reforçar informações de textos didáticos, além de levar a construção de aprendizagens significativas.

As aulas práticas desempenham um papel importante de interação no desenvolvimento de conceitos científicos, além de permitir que os estudantes aprendam como abordar objetivamente o seu mundo e como desenvolver soluções para problemas complexos (LUNETTA, 1992).

Porém, se levarmos em consideração a relevância das atividades práticas dentro do ensino das Ciências, percebemos um paradoxo conferido, pois pesquisas na área de ensino sinalizam para a pouca utilização de aulas práticas no processo de ensino-aprendizagem. 
Segundo Sepel (2012), uma série de fatores podem ser a causa desse "sumiço" destas. A autora comenta que a tradição de aulas práticas quase não existe mais, e vai além. Explica que podem ser compreendidas como tradição, pelo fato de que até a primeira metade do século passado, pelo menos as escolas maiores tinham uma sala destinada ao ensino de Ciências, em geral um laboratório didático equipado e ambientado dentro da tradição naturalista. Já, no cenário atual as atividades práticas envolvendo manipulação de equipamentos, materiais e amostras estão na lista de "inovadoras".

Segunda a mesma autora, o professor, quando propõe uma atividade que não seja aula teórica expositiva ou um exercício associado à leitura do livro didático, torna-se inovador. Assim, são qualificados os planejamentos com apresentação de vídeos, filmes, pesquisas na internet, jogos, dramatizações, debates, apresentações de seminários; saídas de campo; visitas; produção de modelos e entrevistas. Sepel (2012) ainda destaca que nas apresentações de aulas inovadoras no ensino de Biologia, pouco tenha efetivamente de "aula prática", considerando-se a definição mais tradicional: atividades com uso de equipamentos ou materiais que serão manuseados pelos alunos, que podem ser descritas pelo termo "hands-on".

Neste contexto, o ensino prático é componente essencial na formação de professores de Ciências que devem aprender a lidar com equipamentos mais elaborados e também improvisar quando as escolas não dispuserem de materiais.

Compreender a natureza das aulas práticas é importante, para que de fato elas se concretizem. Ainda que as atividades de Ciências sejam muito diversificadas, o termo "aula prática" ainda é visto de forma muito reducionista, estando vinculado ao avental e microscópio. Quando o termo é aplicado para o contexto da educação básica não há uma referência clara do que se está mencionando. Desta forma, é fundamental estabelecer algumas diferenças mínimas entre os vários tipos que uma atividade prática possa ter.

Segundo Sepel (2012), na área de Biologia, podemos reconhecer um elenco de práticas que são realizadas, com poucas variações, desde o início do ensino da História Natural. As práticas mais simples são baseadas em observação macroscópica ou microscópica, seguida pelo registro e fotografias ou ilustrações, com descrições detalhadas do observado. Estas são denominadas práticas naturalistas. Trata-se, nesse caso, de trazer a natureza para a sala de aula, permitir a observação do material concreto e compará-lo com as descrições e figuras presentes nos livros.

Um segundo grupo de práticas é constituído quando o objetivo da atividade envolve comparações entre duas ou mais condições, sendo denominadas de práticas demonstrativas. Incluem as atividades com roteiros lineares que levam à obtenção de um resultado previamente conhecido. Dificilmente constituem momentos desafiadores ou desencadeadores de novas questões, pois são adaptadas para permitir que se chegue ao resultado previsto com a maior segurança possível.

Um terceiro grupo de atividades práticas se caracteriza pela natureza essencialmente experimental. A pesquisa será realmente posta em ação e os resultados não são exatamente previsíveis, ainda que possam ser supostos de acordo com as teorias e conceitos gerais da área. Esta permite aos participantes vivenciar a experiência de produzir conhecimento científico em suas diferentes etapas.

Com isso, corroboramos com Possobom, Okada e Diniz (2003) quando discorrem que as práticas podem funcionar como um "poderoso catalisador" no processo de ensinoaprendizagem de novos conteúdos, onde a vivência do sujeito facilita a fixação dos 
conteúdos. Os autores ainda descartam a ideia de que as aulas experimentais servem apenas para ilustrar os processos aprendidos na teoria, sendo esta uma visão ultrapassada.

Devemos ainda entender que as aulas práticas não devem se limitar apenas à manipulação de reagente e/ou objetos dentro do laboratório, existindo uma necessidade da contextualização dos processos históricos filosóficos sobre a construção daquele conhecimento e as ideias por trás da prática que será realizada.

Diante desta abordagem, o presente artigo tem o intuito de investigar sobre as representações que os docentes em formação em biologia possuem sobre as aulas práticas e como estas se fazem presentes quando estes têm a possibilidade de planejarem suas ações em sala de aula, no momento do estágio. Nosso objetivo, neste estudo, é contribuir para uma reflexão crítica em sala de aula universitária e analisar os elementos mais significativos destas representações. Logo, esta representação designa uma forma de conhecimento específico e compreender a mesma é importante, para, a partir dela, instigar a reflexão, a pesquisa e a construção teórica, a fim de poder realimentar, reconstruir e ressiginificar as representações que os docentes em formação apresentam.

\section{Trajetória Percorrida}

O estudo iniciou com uma pesquisa quali-quantitativa, a partir de um questionário, contendo perguntas abertas e fechadas (perguntas previamente formuladas, tendo-se o cuidado de não modificá-las), sobre concepções acerca de aulas práticas no ensino de Ciências na educação básica. Este instrumento de coleta foi direcionado para vinte acadêmicos licenciandos, participantes da disciplina de Estágio Curricular Supervisionado em Ciências Biológicas no Ensino Fundamental II, integrantes do sexto semestre, regularmente matriculados, no primeiro semestre do ano de 2016, curso de Ciências Biológicas da Universidade Federal de Santa Maria, Campus Palmeira das Missões. Esse número correspondeu a $100 \%$ do total de alunos da disciplina naquele período. Num segundo momento, foram investigados os planos de aulas dos alunos estagiários, a fim de identificar as estratégias didáticas utilizadas na sua ação docente e correlacionar os resultados encontrados às concepções dos mesmos no que se refere às aulas práticas.

Optou-se por aplicar um questionário, pois este tipo de metodologia de coleta de dados não é necessário a presença do pesquisador para que o informante responda as questões, garantindo também uma maior liberdade das respostas em razão do anonimato, evitando vieses potenciais do entrevistador, obtendo-se respostas rápidas e precisas. Antes do preenchimento do questionário, os participantes foram informados sobre a proposta do estudo, inclusive sobre a possibilidade de não responderem às questões, caso não quisessem, assinando um termo de consentimento livre e esclarecido.

As folhas foram recolhidas e posteriormente analisadas. O processo utilizado para compreender o pensamento discente sobre a temática apresentada referendou-se na Análise de Conteúdo (Bardin, 2011), pois, por meio dela, torna-se possível descrever, analisar e interpretar as ideias expressas nas respostas fornecidas pelas questões abertas.

Neste trabalho são discutidas as concepções relacionadas aos resultados e as respectivas porcentagens em que foram observados nos questionários (tratamento dos resultados). Com o intuito de melhor apresentar e discutir os dados essas informações foram organizadas em quadro, tabelas e figuras. 


\section{Resultados e discussão}

A análise global das informações provenientes da totalidade dos participantes de alunos em formação docente permitiu inferir algumas considerações acerca do que estes alunos compreendem por aulas práticas, se as consideram importantes, se as desenvolveram durante o estágio e ainda quais são as dificuldades relacionadas ao emprego desta estratégia de ensino. Os resultados possibilitam pensar a proposição de ações a serem discutidas nos cursos de formação docente. Obtivemos para análise, o total de 20 questionários respondidos, e os planos de aulas de todos os acadêmicos envolvidos (quinhentas aulas ministradas), compreendendo $100 \%$ da amostra.

Quando questionados sobre a compreensão que possuem acerca das aulas práticas, foi possível categorizar as concepções em três unidades de análise (categorias) e estas apresentaram subdivisões (subcategorias de análise), que são elucidadas e discutidas a seguir.

Tabela 1. Categorização sobre a compreensão dos acadêmicos estagiários sobre aulas práticas

\begin{tabular}{l|l|c}
\hline \multicolumn{1}{c|}{ QUESTÃO ABERTA } & \multicolumn{1}{|c}{ CATEGORIAS } & $\%$ \\
\hline Nas aulas de ciências são muitas & Associadas ao processo de aprendizagem & $70 \%$ \\
\cline { 2 - 3 } discutidas sob as possibilidades de & Associadas ao método experimental & $10 \%$ \\
aulas práticas. O que você & (laboratório) & \\
\cline { 2 - 3 } compreende por aulas práticas? & $\begin{array}{l}\text { Associadas ao método em si, emprego de uma } \\
\text { estratégia didática }\end{array}$ & $20 \%$ \\
\hline
\end{tabular}

Tabela 2. Concepções sobre aulas práticas associadas ao processo de aprendizagem, entre acadêmicos estagiários de licenciatura em biologia da UFSM - Palmeira das Missões

\begin{tabular}{|c|c|c|}
\hline CATEGORIAS & SUBCATEGORIAS & $\%$ \\
\hline \multirow{4}{*}{$\begin{array}{l}\text { Associada ao processo } \\
\text { de aprendizagem - } 70 \%\end{array}$} & Aulas que facilitam a compreensão da aula teórica & $15 \%$ \\
\hline & $\begin{array}{l}\text { Aulas em que o aluno constrói o conhecimento e ou } \\
\text { expõe os conhecimentos prévios }\end{array}$ & $5 \%$ \\
\hline & Aulas dinâmicas, onde os alunos apalpam o conteúdo & $10 \%$ \\
\hline & $\begin{array}{l}\text { Aulas que oferecem aos alunos uma visualização da } \\
\text { teoria na prática }\end{array}$ & $40 \%$ \\
\hline
\end{tabular}

Tabela 3. Concepções sobre aulas práticas associadas ao processo de aprendizagem, entre acadêmicos estagiários de licenciatura em biologia da UFSM - Palmeira das Missões

\begin{tabular}{|c|c|c|}
\hline CATEGORIAS & SUBCATEGORIAS & $\%$ \\
\hline \multirow{2}{*}{$\begin{array}{c}\text { Associada ao método } \\
\text { experimental } \\
\text { (laboratório) - 10\% }\end{array}$} & Aulas aplicadas através de experimentos & $5 \%$ \\
\hline & $\begin{array}{l}\text { Aulas em que o aluno (a) consegue fazer uso de } \\
\text { equipamentos }\end{array}$ & $5 \%$ \\
\hline \multirow{2}{*}{$\begin{array}{c}\text { Associada ao método } \\
\text { em si, emprego de } \\
\text { estratégia didática - 20\% }\end{array}$} & $\begin{array}{l}\text { Aulas em que fazem o uso de modelos didáticos } \\
\text { relacionado ao assunto }\end{array}$ & $5 \%$ \\
\hline & $\begin{array}{l}\text { Aulas em que se visualizam processos biológicos } \\
\text { químicos e físicos }\end{array}$ & $15 \%$ \\
\hline
\end{tabular}


Os dados revelam que os alunos não apresentaram uma definição clara sobre o que são aulas práticas. Relacionaram sim, o termo aulas práticas, com vantagens no uso destas, oferecidas ao ensino de Ciências.

Podemos observar pelas respostas, que a maioria dos entrevistados (70\%) vinculou a definição de aulas práticas como sendo ferramentas indispensáveis na construção da aprendizagem, elucidando que os participantes entendem a importância das atividades práticas nas aulas de Ciências. Sobre isto, Lunetta (1992) discute que as aulas práticas ajudam o aluno a compreender um conteúdo trabalhado em sala de aula, ampliando sua reflexão sobre os fenômenos que acontecem a sua volta, enfrentamento de situaçõesproblema, e com isso auxiliam na construção de argumentação e a elaboração de propostas.

Penick (1998) considera que as aulas práticas indicam um caráter inovador, tornando o aluno agente ativo investigativo, sendo ele mesmo capaz de construir os seus conhecimentos e tirar suas próprias conclusões. Esta mesma ideia foi apresentada pelos estagiários, quando consideraram que as aulas práticas são aquelas em que o aluno constrói o conhecimento e ou expõe o prévio; "apalpam" o conteúdo e/ou visualizam a teoria associada à prática.

É importante ressaltar, que embora não significativo, ainda há um contingente de $10 \%$ que associam a definição de aulas práticas como sendo exclusiva ao uso de laboratórios ou atividades experimentais. Sepel (2012) corrobora com esta ideia quando comenta que o termo aula prática está fortemente associado a dois elementos: avental e microscópio. Ao considerarmos isto, é importante discutir estas concepções reducionistas que provocam equívocos de associar aulas práticas apenas com laboratórios, não contribuindo para a compreensão do que é a ciência e que esta faz parte do nosso dia a dia. Assim, percebe-se uma limitação no que diz respeito às atividades práticas quando apenas vinculadas ao uso de laboratórios, promovendo uma redução das inúmeras funções atreladas a esta modalidade.

Ainda 20\% dos participantes apontaram que a as aulas práticas compreendem apenas o método em si. A disciplina de Ciências Naturais é uma disciplina na qual a prática não deveria ser desvinculada da teoria. Dentro desse contexto percebe-se que alguns alunos classificaram as aulas práticas como sendo apenas a técnica em si, que segundo a definição do dicionário Aurélio (2010) palavra técnica vem do grego "téchne", que se traduz por "parte de uma arte" ou "ciência prática". Uma técnica é um procedimento que tem como objetivo a obtenção de um determinado resultado, seja na ciência, na tecnologia, na arte ou em qualquer outra área. Ainda, uma técnica é um conjunto de regras, normas ou protocolos que se utiliza como meio para chegar a certa meta. Neste contexto, pode-se dizer que a técnica sem dúvida é importante, mas ressaltamos as ideias apresentadas por Lakatos e Marconi (2010), quando afirmam que o êxito da utilização da técnica vai depender de diversos fatores, que também devem ser trabalhados. Dependerá do observador, da atenção dada aos fenômenos que ocorrem no mundo que o cerca, da perspicácia, do discernimento, do preparo e treino. Ou seja, toda técnica deve estar estruturada e fortalecida dentro de uma teoria na qual fundamenta sua ação, a fidelidade de conhecer a teoria é fator importantíssimo para a pesquisa. O construtivismo, tal como o devemos encarar nas aulas de ciências, deverá ter caráter de interação entre teoria e prática e não deverá privilegiar nem uma nem outra, mas antes a superação entre as duas. 
Entendemos que as aulas práticas são importantes no ensino de ciências, e que quando bem programadas, contribuem para a construção de abstrações acerca dos fenômenos biológicos pelos estudantes, tornando-se espaços de experiências satisfatórias e importante dimensão cognitiva. De acordo com Krasilchick (2011) são essenciais para favorecer um aprendizado eficaz aos alunos. Porém, a mesma autora ainda comenta que o grande problema das aulas práticas de ciências, é que na maioria das vezes não passam de meras demonstrações. Ou seja, protocolos-receitas com resultados identificados previamente. Infelizmente, na maioria das vezes, são organizadas de modo que o aluno siga instruções detalhadas para encontrar as respostas certas e não para resolver problemas, reduzindo o trabalho de laboratório a uma simples atividade manual.

Diante disso, as aulas práticas experimentais têm um lugar insubstituível, pois desempenham funções únicas: permitem que tenham contato direto com os fenômenos, manipulando os materiais e equipamentos e observando organismos. Na análise do processo biológico, verificam concretamente o significado da variabilidade individual e a consequente necessidade de se trabalhar sempre com grupos de indivíduos para obter resultados válidos. Além disso, somente nas aulas práticas os alunos enfrentam os resultados não previstos, cuja interpretação desafia sua imaginação e raciocínio. Assim, os estudantes devem ser orientados acerca do fenômeno a ser observado, despertando-se o entusiasmo, o interesse e o envolvimento.

Quando foi questionado aos alunos sobre a importância de aulas práticas, foi unânime a afirmação de que estas se fazem necessárias e apresentadas por eles, os motivos pelos quais estas são importantes. Os resultados são apresentados na Tabela 4.

Tabela 4. Importância das aulas práticas entre acadêmicos estagiários de licenciatura em biologia da UFSM - Palmeira das Missões

\begin{tabular}{c|l|c}
\hline QUESTÃO ABERTA & \multicolumn{1}{c|}{ CATEGORIAS } & $\%$ \\
\hline \multirow{3}{*}{$\begin{array}{l}\text { Porque é importante a realização } \\
\text { de aulas práticas de biologia no }\end{array}$} & Atua com facilitador & $60 \%$ \\
\cline { 2 - 3 } Ensino fundamental? & Atua como fator motivador & $30 \%$ \\
\cline { 2 - 3 } & Permite o manuseio laboratorial & $5 \%$ \\
\cline { 2 - 3 } & Possibilita visualizar melhor os fenômenos & $5 \%$ \\
\hline
\end{tabular}

Os resultados indicam que $60 \%$ dos entrevistados consideram as aulas práticas como facilitadoras da aprendizagem, que as mesmas constituem um importante instrumento a ser utilizado, podendo levar ao aumento da motivação e consequentemente influírem na solidificação do aprendizado. Estes resultados apresentados estão em consonância com a primeira questão, no que se refere às vantagens apresentadas pelos alunos no uso desta estratégia de ensino.

Guimarães e Boruchovitch (2004) corroboram, afirmando que o aprendizado de determinado conteúdo sempre é facilitado quando acompanhado de interesse e entusiasmo e que ao experimentar o concreto, ocorre o desenvolvimento do raciocínio e a compreensão dos conceitos.

Barbosa, Paulo e Rinaldi (1999) discutem que as aulas práticas são essenciais na aprendizagem de Ciências, uma vez que a boa formação dos estudantes passa por experiências que transcendem o campo teórico e despertam nos alunos a curiosidade e o interesse de investigação dos diferentes componentes da natureza. Entretanto, para que a 
abordagem prática no ensino tenha sucesso é necessário construir uma interação didática em sintonia com os conceitos e modelos científicos.

Hoering e Pereira (2004) complementam, enfatizando que, ao observar o objeto de seu estudo, podendo este ser manipulado e tocado, permite que o aluno entenda melhor, à medida que há uma observação concreta, sendo este observador capaz de construir o conceito e não apenas imaginá-lo.

Sobre isto, Penick (1998) afirma que:

a utilização dessas aulas promove uma visualização daquilo que antes estava presente apenas no imaginário dos alunos, motivando o interesse na compreensão da matéria. Quando os alunos estão pessoalmente envolvidos, aprendem mais, retêm o conhecimento e desenvolvem habilidades de uma forma mais adequada (PENICK, 1998, p. 95).

Lakatos e Marconi (2010) afirmam que as práticas não consistem apenas em ver e ouvir, mas também em examinar fatos e fenômenos que se deseja estudar, facilitando assim ao aluno uma melhor compreensão de tais atividades.

Outro aspecto que deve ser levado em consideração no ensino de ciências, é a aparente falta de interesse dos alunos nas aulas, fruto de um ensino memorístico e sem relação com o dia a dia. Esta falta de motivação da turma acarreta em aulas estressantes para os alunos e para os professores. Nesta perspectiva, 30\% dos alunos atribuíram às aulas práticas, um caráter motivador.

A ausência de práticas relacionadas aos conteúdos teóricos no ensino de Ciências muitas vezes promove no aluno insatisfação e desmotivação gerando obstáculos na aprendizagem. Além da motivação, que depende tanto do professor como também do aluno, para que as aulas práticas tenham sucesso, é necessário preparo prévio das atividades experimentais. É fundamental que o professor esteja familiarizado com a atividade a ser desenvolvida e o reconhecimento do local para realização da mesma, além da associação ao conteúdo que está sendo desenvolvido, para que não seja dissociada prática de teoria.

Ainda, 5\% dos entrevistados consideraram a importância das aulas práticas relacionadas ao manejo laboratorial. Sobre isso, Lakatos e Marconi, (2010) comentam que esta função também é importante, pois o uso de instrumentos adequados possibilita a realização de observações mais refinadas do que aquelas proporcionadas apenas pelos sentidos. Assim, as aulas práticas que se utilizam de experimentos, desempenham um papel importante nos processos observacionais e obriga o investigador a um contato mais direto com a realidade através do manuseio.

As aulas práticas devem contribuir para promover uma visão distinta da tradicionalreprodutiva-positivista de ensino, através da relação indissociável entre teoria e prática. Isso nos remete a compreender que o processo de ensino nas aulas práticas, não pode ser atrelado apenas à concepção de Ciência experimental de forma impositiva, mas desafiador para motivar os alunos a buscar um conhecimento contextualizado e problematizado no e para o ensino de Ciências. 
Tabela 5. Concepç̃̃es sobre a importância de aulas teóricas e práticas entre acadêmicos estagiários de licenciatura em biologia da UFSM - Palmeira das Missões

\begin{tabular}{c|l|c}
\hline QUESTÃO FECHADA & \multicolumn{1}{|c}{ CATEGORIAS } & $\%$ \\
\hline \multirow{4}{*}{ O que é mais importante? } & Somente aulas práticas & $0 \%$ \\
\cline { 2 - 3 } & Somente aulas teóricas & $0 \%$ \\
\cline { 2 - 3 } & Mais aulas teóricas do que práticas & $85 \%$ \\
\cline { 2 - 3 } & Mais aulas práticas do que teóricas & $15 \%$ \\
\cline { 2 - 3 } & Ambas são igualmente importantes & 0 \\
\hline
\end{tabular}

Tabela 6. Concepçães sobre os momentos de ensino na organização de aulas práticas associadas ou não a aulas teóricas na educação básica, entre acadêmicos estagiários de licenciatura em biologia da UFSM - Palmeira das Missões

\begin{tabular}{l|l|c}
\hline QUESTÃO FECHADA & CATEGORIAS & $\%$ \\
\hline Quando as aulas práticas acontecem, como & Antes das aulas teóricas & $15 \%$ \\
\cline { 2 - 3 } $\begin{array}{l}\text { você, acredita ser melhor o desenvolvimento } \\
\text { destas }\end{array}$ & Depois das aulas teóricas & $70 \%$ \\
\cline { 2 - 3 } & Concomitante com as teóricas & $15 \%$ \\
\hline
\end{tabular}

Observando os resultados apresentados, obtivemos um resultado bem curioso, pois 85\% dos entrevistados relataram as aulas teóricas como sendo mais importantes que as aulas práticas; porém, se analisarmos a primeira questão onde os mesmos definiram as aulas práticas como ferramentas indispensáveis na construção do ensino aprendizagem, como podem nesse momento não ser tão relevante; ou seja, o conteúdo teórico aparecer tão dissociado da prática?

O que percebemos, é que as aulas práticas propostas nas escolas normalmente têm como objetivo, complementar as aulas teóricas. Mesmo compreendendo que todas as modalidades são de extrema importância, o que se observa é que se prioriza uma visão dissociativa, onde o professor ou o aluno por algum fator desintegra a teoria da prática. Assim, é necessário haver uma reflexão deste paradigma, pois se de fato as aulas práticas têm um caráter facilitador, devem ser melhores exploradas.

Tanto a teoria quanto a prática assumem papéis importantes. Ambos os termos derivam do grego, possuindo "teoria" o sentido de observar, contemplar, refletir, enquanto a palavra "prática", provinda de "práxis", relaciona-se ao agir (CANDAU e LELIS, 1999). Dentro desta visão, a teoria e prática são dois componentes indissolúveis das "práxis" definida como atividade teórico-práticas, ou seja, tem um lado ideal, teórico e um lado material, propriamente prático, com a particularidade de que só artificialmente, por um processo de abstração, podemos separar um do outro.

A pesquisa mostra ainda que $15 \%$ dos entrevistados relacionaram tanto a prática quanto a teórica, importantes, a ponto de serem aplicadas concomitantemente. Isto nos faz pensar que é possível discutir nos cursos de formação de professores e sensibilizar mais docentes em formação para esta compreensão. Se esse grupo de alunos de fato entendeu e pratica tais atividades, já é um início para desmistificar a ideia que as aulas práticas não são tão importantes quanto às teóricas estabelecendo assim o verdadeiro valor das aulas práticas dentro do ensino.

Questionados sobre qual o melhor momento para desenvolver as aulas práticas, se antes, após, ou em ação conjunta com aulas teóricas, os alunos, novamente mostraram que 
estas não são tão importantes quanto aulas teóricas, pois $70 \%$ responderam que estas devem ser realizadas após.

Fica claro que os alunos compreendem a prática como um momento de comprovação da teoria previamente estudada, decorrentes de aulas que em geral são inicialmente teóricas e posteriormente são aplicados experimentos que levam a entender a existência de tais conceitos/teorias.

Embora, na maioria das vezes, a concepção de professores e alunos esteja veiculada à ideia de que é "através da experimentação ou pela prática que o aluno consegue assimilar o que foi trabalhado na teoria", entendemos esta concepção, como uma visão ultrapassada. Não podemos aceitar a ideia da experiência como serva da teoria, sendo apenas o seu propósito testar hipóteses. Hacking (1992) discorre que a experiência não é uma atividade monolítica, mas uma atividade que envolve muitas ideias, muitos tipos de compreensão, e também muitas capacidades. Ela tem vida própria. Existem ainda muitos professores que pensam ser possível comprovar a teoria através da prática, imaginando ser esta a função da experimentação no ensino.

Silva e Zanon (2000) afirmam que o correto seria imaginar o inverso: que através da prática realizada pelos alunos, se consiga chegar "por descoberta", a uma determinada teoria, ou a repensar a teoria que foi estudada anteriormente, ou até mesmo tentar compreender um determinado conteúdo antes da teoria. Os autores ainda discutem que a relação entre a teoria e a prática é uma via de mão-dupla, na qual se vai dos experimentos à teoria e das teorias aos experimentos, para contextualizar, investigando, questionando, retomando conhecimentos e também reconstruindo conceitos.

Esta dissociação entre teoria e prática contribui para a dificuldade do aluno em relacionar a teoria desenvolvida em sala com a realidade a sua volta. Sobre isso, Reginaldo, Sheid e Güllich (2012) afirmam que considerando que a teoria é construída por conceitos, na maioria das vezes como abstrações da realidade, pode-se inferir que o aluno não sendo capaz de reconhecer o conhecimento científico em situações do seu cotidiano, não é capaz de compreender a teoria. Freire (2011) complementa apontando que para compreender a teoria é preciso experienciá-la. A realização de experimentos, em ciências, representa uma excelente ferramenta para que o aluno faça a experimentação do conteúdo e possa estabelecer a dinâmica e indissociável relação entre teoria e prática.

Quando questionados sobre como percebem a presença das aulas práticas no ensino em ciências nas escolas, 90\% dos entrevistados responderam que estas ocorrem apenas às vezes e 10\% responderam que estas não acontecem, não sendo dada a devida importância a esta estratégia. Assim foram questionados sobre os motivos pelos quais supõem que estas atividades não ocorrem e os receios que os estagiários apresentam enquanto futuros docentes, para que venham a desempenhar as mesmas. 
Tabela 7. Motivos pelos quais as aulas práticas não são desenvolvidas na educação básica, entre acadêmicos estagiários de licenciatura em biologia da UFSM - Palmeira das Missões

\begin{tabular}{l|l|c}
\hline \multicolumn{1}{c|}{ QUESTÃO ABERTA } & \multicolumn{1}{c|}{ CATEGORIAS } & $\%$ \\
\hline Motivos pelos quais as & Educadores não se desafiam e possuem receios & $20 \%$ \\
\cline { 2 - 4 } $\begin{array}{l}\text { aulas práticas não são } \\
\text { desenvolvidas }\end{array}$ & \begin{tabular}{l} 
É difícil fazer algumas práticas em determinadas turmas \\
\cline { 2 - 4 } \\
atividade
\end{tabular} & $\begin{array}{l}\text { A escola não possibilita a realização desse tipo de } \\
\text { ation }\end{array}$ \\
\hline
\end{tabular}

Tabela 8. Desafios aos professores para o desenvolvimento de aulas prática, sentidos pelos acadêmicos estagiários de licenciatura em biologia da UFSM - Palmeira das Missões

\begin{tabular}{|c|c|c|}
\hline QUESTÃO ABERTA & CATEGORIAS & $\%$ \\
\hline \multirow{5}{*}{$\begin{array}{l}\text { Quais os desafios aos } \\
\text { professores para o } \\
\text { desenvolvimento de aulas } \\
\text { práticas? }\end{array}$} & Escolas que não possui laboratórios/ recursos & $45 \%$ \\
\hline & Ser criativo & $25 \%$ \\
\hline & Falta de tempo & $15 \%$ \\
\hline & Aliar a teoria-prática e a realidade dos alunos & $10 \%$ \\
\hline & Domínio da classe & $5 \%$ \\
\hline
\end{tabular}

Os resultados evidenciam algumas dificuldades em serem desenvolvidas aulas práticas em ciências, no âmbito escolar e estão em consonância com diversos pesquisadores. Krasilchik (2011) comenta que mesmo com toda a potencialidade da experimentação em sala, fatores limitantes como falta de tempo para preparação do material e de equipamentos e instalações adequadas, fazem, que esse instrumento didático não seja uma constante no cotidiano escolar. Essas barreiras fazem com que as aulas práticas sejam propostas de maneira insatisfatória.

Sepel (2012) enfatiza que as atividades práticas não são tão comuns em sala de aula, seja ela por dúvidas, ausência de recursos ou formação limitada os professores que não se sentem preparados, nem em termos (teóricos), nem em termos de métodos e técnicas, para o desenvolvimento das mesmas. Além disso, ainda há a dificuldade do professor em aliar a teórica com a prática e com a realidade dos alunos.

No trabalho de Bueno e Kovaliczn (2008), são apontados como dificuldades, falta de tempo para a realização das atividades experimentais, indisciplina dos alunos, precariedade de materiais, falta de espaço e também de recursos humanos apropriados.

Considerando que os alunos entrevistados eram estagiários e estavam desenvolvendo estágio supervisionado nas escolas e ainda que em breve vão poder atuar na docência, os acadêmicos foram questionados sobre a atuação deles no uso de estratégias de aula com caráter prático. Evidenciamos que apesar de 100\% dos entrevistados compreendem que as aulas práticas podem ajudar a melhorar a compreensão do conteúdo, os resultados do desenvolvimento destas durante o estágio não foi proporcional. Apenas $45 \%$ dos licenciados afirmaram que desenvolveram as mesmas em pelo menos metade das aulas ministradas, conforme elucidado abaixo. 
Tabela 9. Aulas práticas desenvolvidas pelos estagiários de licenciatura em biologia da UFSM Palmeira das Missões nas turmas de estágio na educação básica

\begin{tabular}{l|l|c}
\hline QUESTÃO FECHADA & CATEGORIAS & $\%$ \\
\hline Desenvolvimento de & Não desenvolveu aulas práticas & $20 \%$ \\
\cline { 2 - 3 } $\begin{array}{l}\text { aulas práticas pelos } \\
\text { estagiários na educação }\end{array}$ & Desenvolveu raramente aulas práticas & $35 \%$ \\
\cline { 2 - 3 } básica & Desenvolveu em pelo menos metade das suas aulas & $45 \%$ \\
\cline { 2 - 3 } & Desenvolveu em quase todas ou em todas as aulas & $0 \%$ \\
\hline
\end{tabular}

Após os alunos responderem a esta questão, foi realizado um estudo a partir dos planos de aula e planos de ensino dos vinte estagiários. Cada um dos alunos lecionou vinte e cinco aulas no ensino fundamental. Desta forma, foram analisadas as estratégias didáticas utilizadas pelos alunos em cada uma das aulas ministradas, o que totalizaram quinhentas aulas ministradas pelos acadêmicos durante o semestre. As estratégias didáticas utilizadas pelos docentes em formação são apresentadas nas Figuras 1 e 2 e Tabela 10.

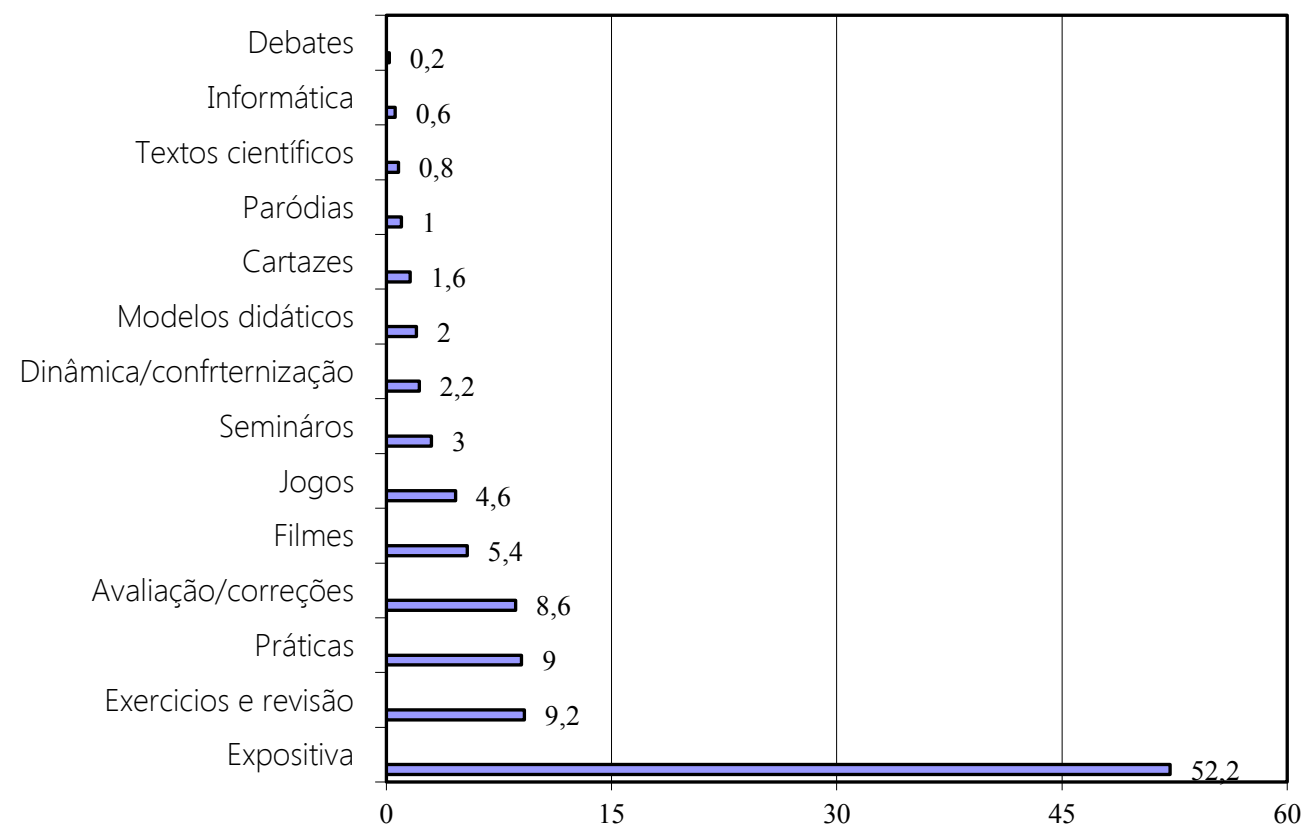

Figura 1. Percentuais de ocorrência das estratégias didáticas utilizadas pelos estagiários nas aulas de ciências

Tabela 10. Distribuição das estratégias didáticas utilizadas nos planos de aula e de ensino dos estagiários de licenciatura em biologia da UFSM - Palmeira das Missões

\begin{tabular}{c|c|c|c|c|c|c|c|c|c|c|c|c|c|c}
\hline Alunos & $\mathrm{AE}$ & $\mathrm{ER}$ & $\mathrm{AP}$ & $\mathrm{AC}$ & $\mathrm{UF}$ & $\mathrm{JD}$ & $\mathrm{SE}$ & $\mathrm{DC}$ & $\mathrm{MD}$ & $\mathrm{CC}$ & $\mathrm{CP}$ & $\mathrm{TC}$ & $\mathrm{PI}$ & $\mathrm{DE}$ \\
\hline $\mathrm{Al} 1$ & 11 & 4 & 0 & 2 & 2 & 1 & 1 & 2 & 0 & 0 & 0 & 1 & 1 & 0 \\
\hline $\mathrm{Al} 2$ & 10 & 1 & 4 & 4 & 0 & 3 & 2 & 0 & 0 & 0 & 0 & 1 & 0 & 0 \\
\hline $\mathrm{Al} 3$ & 15 & 0 & 2 & 3 & 0 & 0 & 2 & 1 & 2 & 0 & 0 & 0 & 0 & 0 \\
\hline $\mathrm{Al} 4$ & 17 & 0 & 1 & 3 & 1 & 0 & 3 & 0 & 0 & 0 & 0 & 0 & 0 & 0 \\
\hline $\mathrm{Al} 5$ & 11 & 7 & 2 & 0 & 0 & 1 & 2 & 2 & 0 & 0 & 0 & 0 & 0 & 0 \\
\hline $\mathrm{Al} 6$ & 12 & 5 & 4 & 2 & 0 & 0 & 0 & 0 & 2 & 0 & 0 & 0 & 0 & 0 \\
\hline $\mathrm{Al} 7$ & 11 & 2 & 3 & 2 & 2 & 2 & 0 & 1 & 0 & 0 & 0 & 0 & 2 & 0 \\
\hline $\mathrm{Al} 8$ & 16 & 0 & 0 & 2 & 2 & 2 & 1 & 0 & 0 & 2 & 0 & 0 & 0 & 0 \\
\hline
\end{tabular}




\begin{tabular}{c|c|c|c|c|c|c|c|c|c|c|c|c|c|c}
\hline Al 9 & 09 & 0 & 4 & 3 & 2 & 3 & 0 & 0 & 2 & 1 & 1 & 0 & 0 & 0 \\
\hline Al 10 & 12 & 2 & 3 & 2 & 2 & 2 & 0 & 1 & 1 & 0 & 0 & 0 & 0 & 0 \\
\hline Al 11 & 11 & 2 & 3 & 2 & 2 & 0 & 2 & 2 & 0 & 0 & 1 & 0 & 0 & 0 \\
\hline Al 12 & 14 & 5 & 3 & 0 & 2 & 1 & 0 & 0 & 0 & 0 & 0 & 0 & 0 & 0 \\
\hline Al 13 & 16 & 2 & 1 & 2 & 0 & 0 & 0 & 1 & 1 & 1 & 1 & 0 & 0 & 0 \\
\hline Al 14 & 17 & 1 & 2 & 0 & 2 & 1 & 0 & 0 & 0 & 2 & 0 & 0 & 0 & 0 \\
\hline Al 15 & 15 & 4 & 4 & 2 & 0 & 0 & 0 & 0 & 0 & 0 & 0 & 0 & 0 & 0 \\
\hline Al 16 & 11 & 3 & 3 & 2 & 2 & 0 & 0 & 1 & 0 & 0 & 2 & 0 & 0 & 1 \\
\hline Al 17 & 13 & 2 & 2 & 2 & 2 & 2 & 0 & 0 & 2 & 0 & 0 & 0 & 0 & 0 \\
\hline Al 18 & 13 & 3 & 2 & 3 & 2 & 0 & 0 & 0 & 0 & 0 & 0 & 2 & 0 & 0 \\
\hline Al 19 & 13 & 2 & 2 & 2 & 2 & 2 & 2 & 0 & 0 & 0 & 0 & 0 & 0 & 0 \\
\hline Al 20 & 16 & 1 & 0 & 3 & 2 & 3 & 0 & 0 & 0 & 0 & 0 & 0 & 0 & 0 \\
\hline TOTAL & 261 & 46 & 45 & 43 & 27 & 23 & 15 & 11 & 10 & 6 & 5 & 4 & 3 & 1 \\
\hline
\end{tabular}

AE - Aulas Expositivas; ER - Exercícios e Revisão (caráter expositivo); AP - Aulas Práticas; AC - Avaliação (Provas) e Correções; FI- Filmes; JD - Jogos Didáticos; SE - Seminários; DC Dinâmica Inicial e Confraternização Final; MD - Modelos Didáticos; CC - Construção de cartazes; CP - construção de Paródias; TC - Textos Científicos; PI - Pesquisas na Informática; DE - Debates.

Como o objetivo principal esteve associado às aulas práticas e como 45\% dos acadêmicos afirmaram que fizeram usos das mesmas em pelo menos metade das aulas ministradas durante os estágios, foram avaliados os tipos de atividades reconhecidas como práticas, desenvolvidas pelos alunos. Cabe salientar que as atividades práticas desenvolvidas e reconhecidas por estes em seus planos de aula, contabilizaram apenas $9 \%$ das atividades desenvolvida. Este resultado mostra uma discrepância considerável, em relação ao posto pelos alunos, apresentado inicialmente como 45\% de atuação.

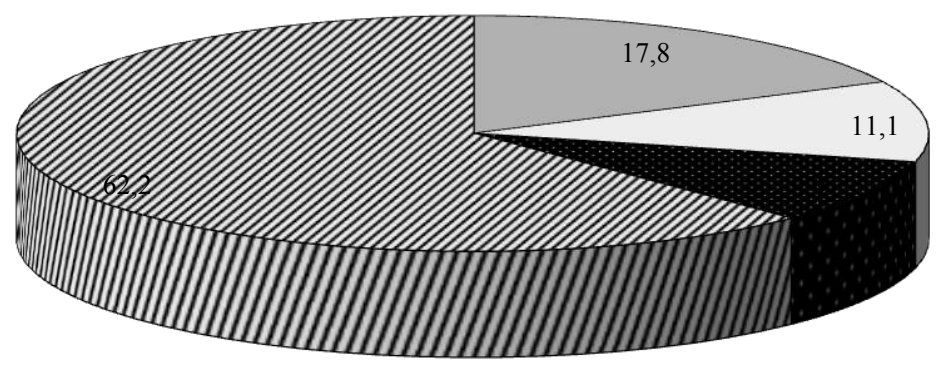

\begin{tabular}{ll|}
\hline DExperimental Laboratório & $\square$ Experimental Demonstrativa \\
-Campo - Naturalista & $\square$ Demonstrativa -Naturalista \\
\hline
\end{tabular}

Figura 2. Percentuais de ocorrência das atividades práticas reconhecidas e desenvolvidas pelos estagiários nas aulas de ciências

Os resultados mostraram que os estagiários não apresentam uma ampla variação nas possibilidades didáticas, fazendo uso demasiado de aulas expositivas, Apesar de importantes, devemos compreender que a utilização única deste método, contribui para a passividade do aluno, não desenvolvendo o espírito crítico e participativo, importantes para o exercício da profissão. 
Pereira et al (2013) descrevem a aula expositiva como sendo uma modalidade didática importante para introduzir um assunto, reforçando uma comunicação fundamental na sala de aula. Esse tipo de metodologia de ensino exige muita concentração dos alunos durante a aula, sendo bastante criticado por existir pouca interação professor/aluno. Cabe salientar, que para que ocorra o processo de ensino-aprendizagem, é fundamental a participação contínua dos estudantes, provocando mobilização, e criando condições para a construção e a elaboração da síntese do objeto de estudo. Muitas vezes, a aula expositiva não favorece o diálogo, podendo para alguns professores, as interrupções, questionamentos, observações, intervenções dos alunos, atrapalharem o desenvolvimento do assunto, fazendo com que o professor perca o controle do processo.

De acordo com a proposta de Laburú, Arruda e Nardi (2003) o pluralismo no uso de recursos e metodologias é a melhor escolha porque respeita diversidade de habilidades, gostos e tendências que existem em uma turma. Viveiro e Diniz (2009) destacam que a diversificação de atividades e de recursos didáticos possibilita a motivação dos estudantes, fator primordial para a aprendizagem. O pluralismo de estratégias assegura mais oportunidades para a construção do conhecimento, outorgando subsídios para que os alunos compreendam melhor o tema que estão estudando.

Atualmente, na didática existe um amplo campo de recursos e estratégias que podem auxiliar o professor na utilização de diferentes modalidades didáticas. O professor dispõe na internet de experimentotecas, kits didáticos, revistas científicas que oferecem atualização sobre os diversos temas científicos, entre outras oportunidades.

Pesquisas na elaboração e avaliação de diferentes modalidades didáticas têm sido desenvolvidas, visando minimizar o desinteresse dos alunos e facilitar o processo de ensino e aprendizagem. Dentre o grupo de professores, encontram-se aqueles que compreendem a importância de explorar os diferentes tipos de recursos e potencializarem suas aulas. Estes fazem uso de modalidades didáticas que permitem associar os conteúdos teóricos tradicionais a temas atuais. Desenvolvem aulas demonstrativas, experimentais, promovem discussões por meio de filmes e documentários, desenvolvem projetos como modo de instigar a pesquisa, entre outros (SILVA et al, 2010). Bazzo (2000) discute que na maioria das vezes, os alunos se deparam com metodologias que nem sempre promovem a efetiva construção de seu conhecimento. Afirma ainda que não haja um método ideal para ensinar os alunos a enfrentar a complexidade dos assuntos trabalhados, mas que existem sim, alguns métodos potencialmente mais favoráveis do que outros, e isso implica no reconhecimento do ambiente e dos recursos nas quais o professor terá disponível para desenvolver suas atividades.

Os Parâmetros Curriculares Nacionais de Ciências Naturais (BRASIL, 1998) apontam que $\mathrm{O}$ uso de diferentes modalidades didáticas, dentre elas, aulas práticas com experimentação são motivadoras para o aluno, diversificando a aprendizagem e a prática do professor, representando uma estratégia para a melhoria no processo de ensino aprendizagem.

Os resultados mostram que os acadêmicos reconheceram quatro atividades desenvolvidas em suas aulas como estratégias de aulas práticas. Foram quarenta e cinco aulas elaboradas, sendo que destas o maior percentual esteve associado às aulas demonstrativas naturalistas, em que o acadêmico levou para a sala de aula, alguns exemplares (principalmente espécimes botânicas e zoológicas) para serem observados 
pelos alunos, em complemento à teoria desenvolvida. Aula de campo (saídas ao ar livre para observação de exemplares e/ou ambiente) totalizou 8,9\%.

É importante salientar que as aulas de campo são recursos metodológicos favoráveis ao desenvolvimento intelectual do aluno. Enriquecem o aprendizado através de observações, levantamentos de dados, impulsionando discussões levantadas por parte do conteúdo que está sendo exposto em sala de aula podendo ser feita uma comparação entre o que o tema tratado está abordando com a realidade apresentada na prática contribuindo para o progresso do ensino-aprendizagem.

Campos (2012) aponta que as saídas a campo podem ser utilizadas como estratégia de ensino de ciências na problematização dos conteúdos, mudando nossa forma de atuar em sala de aula, e possibilitando um novo olhar sobre a natureza e seus recursos, uma vez que além de sua relevância no conteúdo de ciências, a natureza dialoga com nossa relação social.

O autor discute ainda que muitos alunos não vivenciam experiências diretas com a natureza, sendo a saída ao campo uma possibilidade em conhecer um espaço que significa muito mais que um lugar de visita. Por meio do contato direto com a natureza o aluno pode aprender toda a dinâmica do ecossistema que está estudando, domínio que lhe permitirá discutir com segurança e sugerir formas alternativas e ambientalmente sustentáveis, para sua realidade, quando tiver oportunidade de se manifestar.

Aulas experimentais não tiveram o mesmo destaque que as outras modalidades. Sepel (2012) afirma que é fácil justificar porque aulas práticas que envolvem atividades de laboratório ou experimentos não têm muito destaque no rol dos planejamentos inovadores. Basta lembrar que na maioria das escolas não existem laboratórios para aulas das áreas de Ciências, sob forma de salas específicas para Biologia, Química ou Física. E quando apresentam esse espaço, em geral é subutilizado por não ter condições de funcionamento pleno, devido a carências variadas, incluindo-se na lista a falta de equipamentos, de material de consumo, bem como de recursos humanos para manter e pôr em funcionamento as atividades práticas.

Vale reforçar que atividades práticas requerem um maior tempo de realização e uma maior preparação por parte do professor. Os trabalhos práticos devem objetivar privilegiar a participação do aluno na construção do conhecimento. Nesta perspectiva, os alunos não são meros expectadores e receptores de conceitos, teorias e soluções prontas. Pelo contrário, eles participam da resolução de um problema proposto pelo professor ou por eles mesmos, elaboram hipóteses, coletam dados e os analisam, elaboram conclusões e compartilham os seus resultados com os colegas. O professor se torna um questionador, conduzindo perguntas e propondo desafios aos alunos para que estes levantem suas próprias hipóteses e proponham possíveis soluções para o problema (GALIAZZI E GONÇALVES, 2004).

Por fim, outro ponto que merece destaque neste estudo, é o tempo destinado às aulas em que se fizeram uso de exercícios de fixação e avaliações.

Infelizmente, apesar das inúmeras críticas, o ensino de ciências ainda se caracteriza muito, pela memorização do "ensino tradicional", exigindo ao aluno que decore diferentes conceitos e pratique listas com enorme quantidade de exercícios (mecanização). A insistência exagerada deste tipo de atividade, como se mais nada contasse, impede muitos alunos de adquiriram outras competências. 
Dewey (1978) critica a educação pela instrução e propunha a educação pela ação; criticava severamente a educação tradicional, principalmente no que se refere à ênfase dada ao intelectualismo e à memorização. Defendia uma educação com a finalidade de propiciar à criança condições para que resolvesse por si própria, os seus problemas.

Freint segundo Oliveira (2006) também questionou as tarefas escolares repetitivas e cansativas, opostas aos jogos, atividades lúdicas e agradáveis, apontando como essa dualidade, presente na escola, reproduz a dicotomia entre a aprendizagem e o prazer.

Oliveira (2006) ainda argumenta que o modelo tradicional de ensino, que se desenvolveu ao longo do século XIX, e que subsiste em muitas organizações escolares, é baseado em metodologias expositivas, na fixação e memorização, pouca aplicabilidade do conteúdo na realidade e na vivência do aluno. É um ensino basicamente livresco, com baixo nível de interação do sujeito com o objeto de conhecimento. Os alunos acumulam saberes, são bem avaliados em suas provas periódicas, mas não conseguem transferir o que aprenderam para situações reais de suas vidas. O sistema de avaliação mede a quantidade de informação absorvida e enfatiza a memorização, a reprodução do conteúdo por meio de exercícios, privilegia a preparação para o vestibular desde o início da vida escolar.

Diante disso, à medida que é observado um grande número de aulas (17,8\%), desenvolvidas pelos estagiários com esta peculiaridade, este resultado nos faz refletir sobre a maior necessidade em serem discutidas com maior ênfase, tais questões em curso de formação de professores. Pois os resultados mostram que muitas vezes estamos reproduzindo um sistema atual, na mesma medida em que estamos criticando e apontando as necessidades de mudanças.

\section{Considerações Finais}

A análise dos resultados permitiu inferir algumas considerações acerca de como estes alunos em formação docente compreendem as aulas práticas.

Evidenciamos que as aulas práticas são compreendidas como ferramentas indispensáveis para um aprendizado efetivo, sendo reconhecido pelos acadêmicos e pela literatura, o papel facilitador na aprendizagem e o fator motivador que seu uso exerce sobre os estudantes.

No entanto, observamos que os estagiários ainda não apresentam uma percepção clara do que são aulas práticas, pois se de fato fossem compreendidas como facilitadoras, os resultados em sala e aula, no momento em que Ihes foi dada a oportunidade de proporem e elaborarem suas aulas teria sido diferente do encontrado. $O$ uso das mais distintas estratégias didáticas deveria estar presente, o que não foi constatado neste estudo.

As aulas práticas são essenciais na aprendizagem de ciências, uma vez que a boa formação dos estudantes passa por experiências que transcendem o campo teórico e despertam nos alunos a curiosidade e o interesse de investigação dos diferentes componentes da natureza. Entretanto, para que a abordagem prática no ensino tenha sucesso é necessário construir uma interação didática em sintonia com os conceitos e modelos científicos (BARBOSA, 1999).

Pensando assim, o docente em formação precisa cada vez mais alicerçar o conceito de atividades práticas para atingir o que se busca. Enquanto houver essa contradição fica difícil de estabelecer o valor das tais atividades. Sobre isto, Candau (1997) afirma que a formação 
básica de todo e qualquer professor se dá pelo domínio do conteúdo específico, a partir do qual é possível construir a competência pedagógica.

Desta forma, faz-se justo a preocupação por parte dos pesquisadores quanto à formação dos professores. Zimmermann e Bertani (2003) afirmam serem necessários ao professor em sua formação, discussões que visem romper com as concepções impostas e cultivadas por um sistema, permitindo a ele estabelecer o seu papel - que não é somente o de "dar aula" - mas o de ser um profissional reflexivo e crítico, compromissado com a formação do aluno, tanto em nível intelectual quanto em nível humano. Assim, promover reflexões sobre a natureza das aulas que tem sido desenvolvida nos estágios é um bom caminho para provocarmos mudanças nas aulas de ciências na educação básica.

Concluímos este artigo ressaltando que as aulas práticas não são a solução para os diversos problemas enfrentados no ensino de biologia, mas constituem um importante instrumento a ser utilizado, e uma vez utilizado com critério, pode levar ao aumento da motivação e consequentemente influírem na solidificação do aprendizado.

\section{Referências}

BARBOSA, J. O.; PAULO, S. R.; RINALDI, C. Investigação do Papel da Experimentação na Construção de Conceitos em Eletricidade no Ensino Médio. Caderno Catarinense de Ensino de Física, Florianópolis, v. 16, n. 1, p. 105-122, 1999.

BARDIN, L. Análise de conteúdo. São Paulo: Edições 70, 2011, 229 p

BAZZO, V. L. Para onde vão as licenciaturas? A formação de professores e as políticas públicas. Educação, Santa Maria, RS, v. 25, n. 1, p. 53-65, 2000.

BRASIL, MEC. Parâmetros Curriculares Nacional. Ciências Naturais. Brasília: Ministério da Educação - Secretaria de Educação Fundamental, 1998.

BUENO, R. S. M.; KOVALICZN, R. A. O ensino de Ciências e as dificuldades das atividades experimentais. 2008. p. 18, 19. Disponível em: http://www.diaadiaeducacao.pr.gov.br /portals/pde/arquivos/23-4.pdf. Acesso em: set. 2016.

CAMPOS, C. R. P. A saída a campo como estratégia de ensino de ciências: reflexões iniciais. Revista Eletrônica Sala de Aula em Foco, v. 1, p. 33-38, 2012.

CANDAU, V. M. e LELIS, I. A. A Relação Teoria-Prática na Formação do educador. In: CANDAU, V. M (Org.). Rumo a uma Nova Didática. 10 ed. Petrópolis: Vozes. 1999. p. 56-72.

CARRAHER, D. W.; CARRAHER, T. N. e SCHLIEMANN, A. D. Caminhos e descaminhos no ensino de ciências. Ciência e Cultura, São Paulo, v. 37, n. 6, jun. p.889-896, 1985

CARRETERO, M. Constructivismo y Educación. Zaragoza: Editorial Luis Vives, 1993.

DEWEY, J. Vida e Educação. 10. ed. São Paulo: Melhoramentos, 1978.

FRACALANZA, H.; AMARAL, I. A.; GOUVEIA, M. S. F. O ensino de Ciências no Primeiro Grau. São Paulo: Atual, 1987. 124 p.

FREIRE, P. Pedagogia da Autonomia. 43 ed. Rio de Janeiro: Paz e Terra, 2011.

GALIAZZI, M. C.; GONÇALVES, F. P. A natureza pedagógica da experimentação: uma pesquisa na licenciatura em Química. Química Nova, v.27, n.2, p.326-331, 2004 
GUIMARÃES, S. É. R. e BORUCHOVITCH, Evely. O Estilo Motivacional do Professor e a Motivação Intrínseca dos Estudantes: Uma Perspectiva da Teoria da Autodeterminação. Psicologia: Reflexão e Crítica, 2004, 17(2), pp.143-150

GOLDSCHMIDT, A. I. el al. Entre riscos e rabiscos: concepções sobre a imagem docente. Ensino de Ciências e Tecnologia em Revista, v. 6, n. 1. jan/jun 2016.

HACKING; I. Refazer o mundo. In: A Ciência como Cultura, 103-118. Lisboa: Imprensa Nacional Casa da Moeda, 1992.

HODSON, D. Hacia um enfoque más crítico del trabajo de laboratório. Enseñanza de las Ciencias, v.12, n. 13, p.299-313, 1994.

HOERNIG, A.M. e PEREIRA A.B. As aulas de Ciências Iniciando pela Prática: O que Pensam os Alunos. Revista da Associação Brasileira de Pesquisa em Educação em Ciências, v.4, n.3. set/dez 2004, p.19-28.

HOLANDA, A. B. Míni Dicionário Aurélio da Língua Portuguesa. Positivo Editora. 8 a Ed. 2010

KRASILCHIK, M. Prática de Ensino de Biologia. São Paulo: Universidade de São Paulo, 2011, 4 ed.

LABURÚ, C. E.; ARRUDA, S. M. e NARDI, R. Pluralismo metodológico no ensino de ciências. Ciência \& Educação, v. 9, n. 2, p. 247-260, 2003. Disponível em: http://www.scielo.br/pdf/ciedu/v9n2/07.pdf. Acessado em junho de 2016.

LAKATOS, E. M. e MARCONI, M. A. Fundamentos de metodologia científica. 7. ed. São Paulo: Atlas, 2010.

LUNETTA, V. N. Atividades práticas no ensino da ciência. Revista Portuguesa de Educação, v.2, n.1, p.81-90, 1992.

OLIVEIRA, C. L. Significado e contribuições da afetividade, no contexto da Metodologia de Projetos, na Educação Básica. Dissertação de Mestrado, CEFET-MG, Belo Horizonte. MG, 2006.

PENICK, J. E. Ensinando alfabetização científica. Educar em Revista Curitiba, n. 14, p. 91-113, 1998. Disponível em: http://www.scielo.br/pdf/er/n14/n14a07.pdf. Acessado em junho de 2016.

PEREIRA, M. G. et al. Modalidades didáticas utilizadas no Ensino de Biologia na educação básica e no ensino superior. In: $\mathrm{X}$ Jornadas Nacionales $\mathrm{V}$ Congreso Internacional de Enseñanza de la Biología Entretejiendo la enseñanza de la Biología en una urdimbre emancipadora. Córdoba. Argentina, 2012.

POSSOBOM, C.C.F.; OKADA, F.K. e DINIZ, R.E.S. As atividades práticas de laboratório no ensino de Biologia e Ciências: relato de uma experiência. In: Universidade Estadual Paulista Pró-Reitoria de Graduação. (Org.). Núcleos de Ensino. São Paulo: Editora da UNESP, v. 1, p. 113-123, 2003.

POZO, J. I. e GÓMEZ CRESPO, M. Á. Aprender y enseñar ciencia. Madrid: Ediciones Morata, 1998. 
REGINALDO, C. C.; SCHEID, N. M. J. e GULLICH, R. I. C. O Papel Da Experimentação no Ensino de Ciências. In: Anais do II Congresso Internacional De Educação Científica E Tecnológica, 2012, Santo Ângelo: Ediuri, 2012. v. 2. p. 01-01.

SEPEL, L. M. N. História da ciência e atividades práticas: proposta para formação inicial de docentes. Tese de Doutorado. Universidade Federal de Santa Maria. Santa Maria, 2012.165 p. Disponível em <http://w3.ufsm.br/ppgecqv/Docs/teses/Lenira.pdf>. Acessado em 18 de agosto. 2016.

SILVA, B. B. T. N. et al. Utilização das modalidades didáticas pelos professores de Biologia de uma escola Estadual em Pernambuco. In: X Jornada de Ensino, Pesquisa e Extensão - JEPEX - UFRPE. Recife. 2010

SILVA, L. H. A e ZANON, L. B. Experimentação no ensino de ciências. In: SCHNETZER, R. P. e ARAGÃO, R. M. R. (Orgs.) Ensino de Ciências: fundamentos e abordagens. Campinas: V Gráfica, 2000. p. 120-153.

VIVEIRO, A. e DINIZ, R. E. S. Atividades de campo no ensino das ciências e na educação ambiental: refletindo sobre as potencialidades desta estratégia na prática escolar. Ciência em tela. v. 2 n.1, 2009

ZIMMERMANN, E. e BERTANI, J. A. Um novo olhar sobre os cursos de formação de professores. Cad.Bras.Ens.Fís., v.20, n.1: 43-62, 2003. 